\section{The new implant system on the block}

Are you looking for implants that provide predictable, proven results?

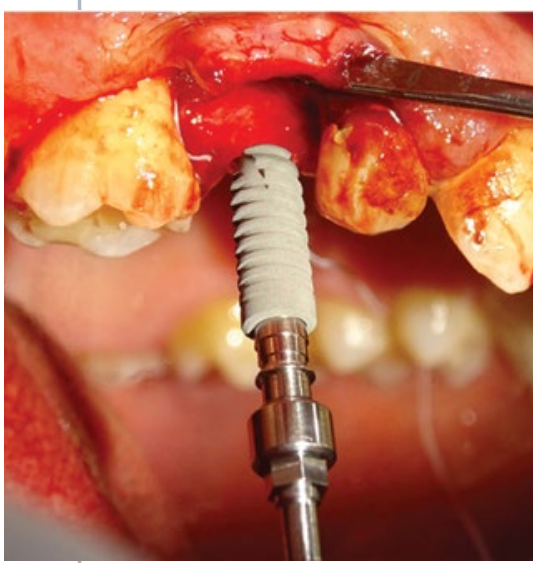

Myplant Two implants from myplant could be exactly what you're searching for. Building off a design that has been perfected over 30 years, Myplant Two implants offer users a number of enticing benefits.

Developed to be placed subcrestally for better aesthetics, the cutting-edge design of the implants alongside the simple drilling protocols instantly increase primary stability in all qualities of bone.

Furthermore, as the implants feature a unique inner cone design, the seal between the abutment and the implant is virtually bacteria-proof, meaning that there is less chance of bacterial build up resulting in implant failure.

To find out more, visit www.myplant-dental.com, email order@myplant-dental.com or call 08007797879.

\section{Precisely fitting, digitally designed removable} partial dentures

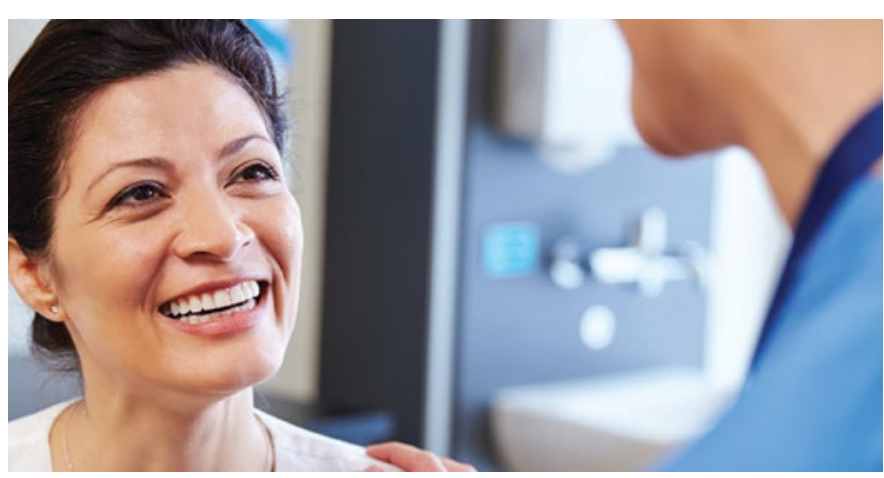

Offer your patients a thin, lightweight RPD frame made from Ultaire AKP for a natural, comfortable feel.

Ultaire AKP is a new generation, polymer-based material that has been custom developed by Solvay Dental 360. It provides patients with a viable alternative to metal, which is strong, durable and biocompatible.

RPDs fabricated from Ultaire AKP feature discreet clasp designs, which engage with undercuts and produce a snap-in fit to maintain excellent retention and outstanding aesthetic results. With the accuracy and design possibilities that can be achieved, Ultaire AKP is the way forward.

To book a Solvay Dental 360 Professional Lunch and Learn or to find more information Ultaire AKP and Dentivera milling discs, visit www.solvaydental360.com.

\section{Stabilise teeth quickly}

Comcord is a matrix of HDPE fibres and advanced composite. The unique combination means that stabilising teeth can be achieved very quickly.

Using Comcord is much easier with fewer stages than existing materials. Dental Life Sciences (DLS) say that Comcord is simple to apply. The teeth to be stabilised are first etched then bonded, thereafter the Comcord strip is applied and cured one tooth at a time.

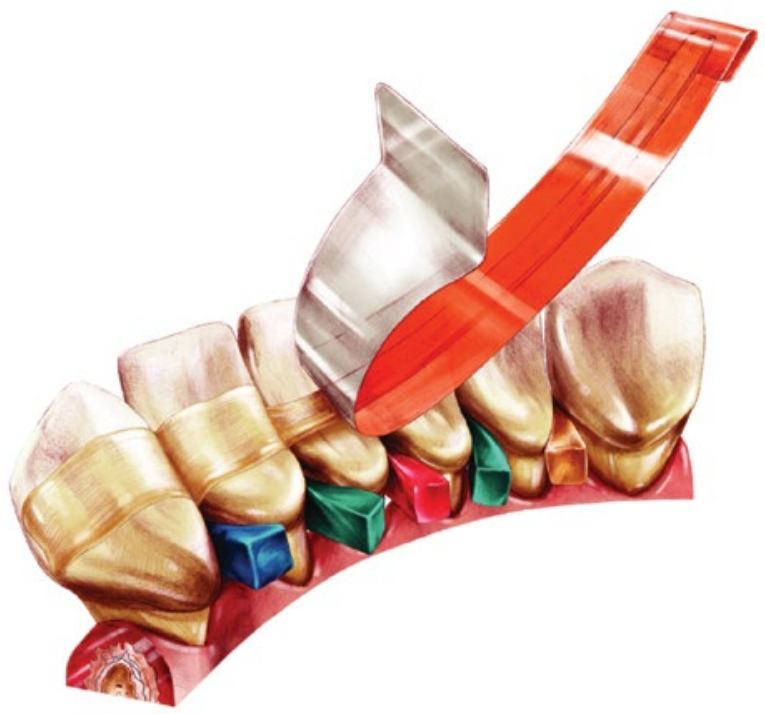

The product is presented as a $6 \mathrm{~cm}$ strip covered in an orange film to protect it from accidental cure. These strips can be cut and shaped according to clinical requirements. DLS say that the material can be used not only for splinting but for indications in other areas of restorative dentistry where additional strength is needed. For example, bridges, large fillings and core build-ups.

Comcord is manufactured by Dental Life Sciences and sold at Introdent and currently on special offer: three packs for $£ 100$ or $£ 41.99$ for a single pack. For more information call Andy 07739 463726 or visit www.introdent.com.

\section{Beat back bacteria}

Many patients neglect flossing and interproximal brushing due to issues of comfort, inconvenience and difficulty. Yet the potential for bacteria to affect their oral and general health is great, so ensuring good oral hygiene is invaluable.

Waterpik Water Flossers cut through the hassle and help patients to remove debris and bacteria even in hard to reach places. Plus, the easy to use Waterpik Water Flosser has been found to be significantly more effective than interdental brushes for improving gingival health.

There's a Waterpik product for everyone, so find out more today.

For more information on Waterpik products please visit www. waterpik.co.uk. Waterpik products are available from Amazon, Asda, Boots and Superdrug online and in stores across the UK and Ireland. 